\title{
Perfil de isolamento microbiano em cães com otite média e externa associadas
}

\author{
[Profile of microorganisms isolated from dogs with associated media and extern otitis] \\ L.C. Oliveira ${ }^{1}$, R.S.N. Brilhante ${ }^{1}$, A.M.S. Cunha ${ }^{2}$, C.B.M. Carvalho ${ }^{1}$ \\ ${ }^{1}$ Departamento de Patologia e Medicina Legal - UFC \\ Rua Alexandre Baraúna, 949 \\ 60430-160 - Fortaleza, CE \\ ${ }^{2}$ Departamento de Estatística e Matemática Aplicadas - UFC - Fortaleza, CE
}

\begin{abstract}
RESUMO
Comparou-se o perfil de isolamento microbiano de amostras coletadas de cães com otite média (OM) e externa (OE) associadas. Sessenta e quatro cães com otite média e externa foram avaliados durante 10 meses. Amostras dos condutos auditivos externos foram coletadas com auxílio de swabs estéreis e aquelas do ouvido médio pela técnica cirúrgica da osteotomia da bula timpânica. Os microrganismos foram cultivados e identificados de acordo com os métodos previamente descritos, e a susceptibilidade a antimicrobianos avaliada pelo método de difusão em ágar estabelecido pelo National Committee for Clinical Laboratory Standards. Bactérias anaeróbias estritas não foram isoladas em qualquer amostra. Todas as amostras de OE mostraram crescimento bacteriano e/ou fúngico. $\mathrm{Na} \mathrm{OM}$, a positividade nas culturas foi de $48 \%$. Os microrganismos mais isolados na OE foram: Bacillus sp. (26,9\%), $M$. pachydermatis $(22,2 \%)$ e $S$. intermedius $(21,7 \%)$; na OM foram: S. intermedius $(32,5 \%)$, S. aureus subsp. aureus $(22,5 \%)$ e bacilos Gram-negativos não fermentadores (10,0\%). Observou-se alguma diferença no perfil de isolamento entre os quadros de OM e OE em 96,7\% dos animais. Verificou-se elevada resistência de cepas de $S$. intermedius à penicilina $\mathrm{G}$, ampicilina, eritromicina, tetraciclina e clindamicina.
\end{abstract}

Palavras-chave: cão, otite, antibiograma

\begin{abstract}
The isolation pattern of samples collected from dogs with both media (OM) and extern otitis (OE) was compared. Sixty-four dogs suffering from those conditions were studied over a 10-month period. Samples from the external ear were collected with sterile swabs while those from the middle ear were collected by osteotomy of the tympanic bulla. The microorganisms were cultured and identified according to methods previously described and to the susceptibility of antimicrobials according to the National Committee for Clinical Laboratory Standards agar diffusion test. Anaerobic bacteria were not isolated in any sample. All samples from OE showed bacterial and/or fungal growth. Concerning media otitis, this percentage was $48 \%$. The most common microorganisms isolated from OE were Bacillus sp. (26.9\%), $\mathrm{M}$. pachydermatis $(22.2 \%)$ and $\mathrm{S}$. intermedius $(21.7 \%)$ and those from OM were $\mathrm{S}$. intermedius $(32.5 \%), \mathrm{S}$. aureus subsp. aureus (22.5\%) and non-fermentative Gram-negative rods (10.0\%). Some difference was observed in the isolation pattern between media and extern otitis in $96.7 \%$ of the animals. High resistance rates of $\mathrm{S}$. intermedius strains to penicillin $G$, ampicillin, erythromycin, tetracycline and clindamycin were found.
\end{abstract}

Keywords: dog, otitis, antibiogram

Recebido em 11 de fevereiro de 2005

Aceito em 21 de novembro de 2006

E-mail: liscristina@agricultura.gov.br 


\section{INTRODUCÃO}

A otite externa (OE) é uma doença de etiologia multifatorial, com numerosos fatores predisponentes que se relacionam com a infecção em cães (Greene, 1993).

A microbiota residente do ouvido externo canino é constituída por cocos Gram-positivos, bastonetes Gram-positivos e leveduras da espécie $M$. pachydermatis (Bonates, 2003). Quanto ao ouvido médio canino, poucos estudos têm sido realizados na área de microbiologia devido à dificuldade de acesso a esse local. Matsuda et al. (1984) sugerem a presença de uma microbiota normal no ouvido médio, derivada da faríngea, que ascende à tuba auditiva, a qual seria constituída por enterobactérias, estafilococos e leveduras.

Os microrganismos mais freqüentemente isolados de $\mathrm{OE}$ canina são $M$. pachydermatis e $S$. intermedius (Kiss et al., 1997) associados ou não a bastonetes Gram-negativos, embora outras espécies tenham sido descritas. Quanto à otite média (OM) canina, destacam-se S. intermedius, Streptococcus sp. e Pseudomonas sp. (Cole et al., 1998).

Em geral, a OM decorre de uma otite externa crônica (Leite, 2003) que evolui com ruptura do tímpano e distribuição bilateral. Cole et al. (1998) diagnosticaram $\mathrm{OM}$ em $82,6 \%$ dos quadros de $\mathrm{OE}$ canina e relataram diferença nos microrganismos isolados e nos padrões de resistência antimicrobiana em $89,5 \%$ dos casos quando compararam amostras coletadas na porção horizontal do ouvido externo e amostras do ouvido médio. Os autores sugerem que resultados de cultura de microrganismos e seus perfis de sensibilidade a antimicrobianos obtidos a partir de material de $\mathrm{OEC}$ não podem ser extrapolados para direcionar o tratamento da OM.

Considerando-se a escassez de informações acerca dos aspectos microbiológicos envolvidos nos quadros de otite média canina no Brasil, o objetivo do presente trabalho foi comparar o perfil de isolamento microbiano de cães com otite média e externa associadas.

\section{MATERIAL E MÉTODOS}

Entre agosto de 2003 e março de 2004, 64 cães com otite externa e média associadas foram estudados. Os cães eram todos adultos, sendo 43 do sexo masculino e 21 do sexo feminino, das seguintes raças: sem raça definida $(\mathrm{n}=49)$, Pastor Alemão $(\mathrm{n}=6)$, Maltês $(\mathrm{n}=3)$, Dálmata $(\mathrm{n}=1)$, Pointer $(\mathrm{n}=1)$, Weimaraner $(\mathrm{n}=1)$, Labrador $(\mathrm{n}=1)$, Fila Brasileiro $(\mathrm{n}=1)$ e Husky Siberiano $(\mathrm{n}=1)$. As amostras foram oriundas de cães abandonados nas ruas destinados à eutanásia e cedidos pelo Centro de Controle de Zoonoses Fortaleza, CE. Os animais foram examinados no dia anterior à coleta de amostras. $\mathrm{O}$ critério para inclusão no grupo-teste foi a presença de otite externa e de características sugestivas de otite média. Foi considerado otopata o animal que apresentava dois ou mais sinais indicativos de inflamação do epitélio do ouvido externo (erosão, pontos hemorrágicos, pólipos, estenose parcial ou total do conduto auditivo e alterações na cor, odor, aspecto e/ou quantidade da secreção auricular) e do ouvido médio (perda parcial ou total da integridade da membrana timpânica e presença de alterações em suas características normais, tais como abaulamento, alterações de cor e hemorragia).

A partir do ouvido externo, foram coletadas quatro amostras de secreção auricular da sua porção horizontal com auxílio de $s w a b$ estéril e otoscópio (Gowlland (C) com cânulas de uso veterinário, sendo: $1^{\text {a }}$ amostra - citologia e bacterioscopia, $2^{\mathrm{a}}$ amostra - cultivo de bactérias anaeróbias estritas, $3^{\text {a }}$ amostra - cultivo de bactérias anaeróbias facultativas e $4^{\mathrm{a}}$ amostra cultivo de fungos. Para a coleta de amostras do ouvido médio, utilizou-se a técnica de osteotomia de bula timpânica - Método de McNutt-McCoy (Smith e Waldron, 1993), sendo as amostras coletadas com auxílio de $s w a b$ estéril (para cultivo de bactérias anaeróbias estritas e bacterioscopia/citologia) e de seringa e agulha estéreis (para cultura de bactérias anaeróbias facultativas e cultura de fungos).

As amostras foram processadas para isolamento e identificação de microrganismos e testes de susceptibilidade a antimicrobianos. As destinadas ao cultivo de bactérias anaeróbias estritas, as bactérias anaeróbias facultativas e o cultivo de fungos foram transportados ao laboratório em meios para transporte Cary e Blair modificado, Stuart e Sabouraud líquido suplementado com cloranfenicol $(0,05 \%)$. O tempo decorrido entre a coleta e o processamento das amostras foi de no máximo três horas. Para o isolamento de bactérias anaeróbias facultativas, as amostras foram semeadas em Columbia ágar suplementado com 5\% 
de sangue de carneiro (ágar sangue), manitol salt agar, MacConkey agar e brain heart infusion broth (BHIB). As culturas foram incubadas a $37^{\circ} \mathrm{C}$ por 24-48h em aerobiose e microaerofilia. Para o isolamento de bactérias anaeróbias estritas, os meios utilizados incluíram: BHI agar ${ }^{1}$, bacteroides bile esculin agar, phenylethyl alcohol agar ${ }^{1} \mathrm{e}$ $\mathrm{BHIB}^{2}$. As culturas foram incubadas a $37^{\circ} \mathrm{C} \mathrm{em}$ anaerobiose. Para o isolamento fúngico, as amostras foram semeadas em Sabouraud agar (SA), SA suplementado com cloranfenicol $(0,05 \%)$, SA suplementado com cloranfenicol $(0,05 \%)$ e cicloeximida $(0,05 \%)$ e Dixon agar e mantidas à temperatura ambiente por 15 dias. As espécies bacterianas foram identificadas com base na morfologia de colônia, coloração pelo método de Gram, produção de pigmento, hemólise no ágar sangue e provas bioquímicas (Murray et al., 2002). Microrganismos fúngicos foram identificados com base na morfologia de colônia, crescimento em ASG, características microscópicas e provas bioquímicas (Sidrim e Moreira, 1999).

Para realização dos testes de susceptibilidade a antimicrobianos, utilizou-se o método de difusão (Performance...,1997). As cepas utilizadas para controle de qualidade foram Staphylococcus aureus ATCC 25923 e Escherichia coli ATCC 25922. Os antimicrobianos testados incluíram: amicacina, ampicilina, canamicina, cefalotina, cefoxitina, ciprofloxacina, clindamicina, cloranfenicol, enrofloxacina, eritromicina, gentamicina, imipeném, neomicina, oxacilina, penicilina $\mathrm{G}, \quad$ polimixina $\mathrm{B}$, sulfametoxazol/trimetoprima, ticarcilina, tobramicina, tetraciclina e vancomicina. A ocorrência de cepas de Staphylococcus sp. resistentes à oxacilina foi confirmada mediante prova de agar screen plate, segundo estabelecido pelo National Committee for Clinical Labortatory Standarts (Performance..., 1997).

Os esfregaços destinados à citologia e bacterioscopia foram corados pelos métodos de Giemsa e Gram, respectivamente. As lâminas foram inicialmente avaliadas em menor aumento (x10) para localização dos campos mais significativos. Uma vez localizados, eram escolhidos 10 campos representativos, os quais eram avaliados em imersão quanto à presença de: eritrócitos, células inflamatórias, ceratinócitos, células cúbicas, leveduras e bactérias.

\footnotetext{
${ }^{1}$ Suplementado com $5 \%$ de sangue de carneiro + hemina -

$5 \mu \mathrm{g} / \mathrm{ml}+$ menadione $-1 \mu \mathrm{g} / \mathrm{ml}$

${ }^{2}$ Suplementado com hemina $-5 \mu \mathrm{g} / \mathrm{Ml}+$ menadione $-1 \mu \mathrm{g} / \mathrm{ml}$
}

\section{RESULTADOS}

Os sinais clínicos mais freqüentes nos ouvidos dos cães otopatas foram: lesões no pavilhão auricular $(72 \%)$, presença de otalgia $(12 \%)$ e alteração do posicionamento do pavilhão auricular (12\%). No exame otoscópico, observaram-se: pontos hemorrágicos $(87 \%)$, erosão no epitélio do conduto auditivo (80\%) e presença de corpos estranhos no conduto auditivo (43\%). Quanto à membrana timpânica, a otoscopia revelou: ruptura parcial ou total (18\%) e não visualização (20\%). Nos casos em que a membrana timpânica estava íntegra $(62 \%)$, as alterações observadas foram: abaulamento $(82,3 \%)$, hemorragia $(14,5 \%)$ e espessamento $(3,2 \%)$.

$\mathrm{Na}$ citologia do ouvido externo, observou-se presença de: eritrócitos $(21 \%)$, células inflamatórias (73\%) e células cúbicas $(75 \%)$, bem como um número superior a seis ceratinócitos/campo (62\%) e a dez células leveduriformes/campo (29\%). A visualização de microrganismos nos esfregaços corados pelo Gram foi compatível com os resultados das culturas. No tocante ao ouvido médio, a citologia se revelou falha no auxílio ao diagnóstico de OM, não se podendo observar, na maioria dos casos, sequer os elementos constitutivos do epitélio auditivo, e as bacterioscopias mostraram-se negativas em $91 \%$ dos casos.

Dos 64 cães estudados, 30 (48\%) demonstraram colonização microbiana no ouvido médio, enquanto em $100 \%$ dos animais foram isolados microrganismos no ouvido externo. Notou-se ainda que os quadros de OM foram predominantemente relacionados à infecção monomicrobiana ( $77 \%$ dos casos positivos) enquanto nos animais com $\mathrm{OE}$ as infecções foram polimicrobianas $(100 \%)$ com associação de 2 a 5 microrganismos.

Os agentes bacterianos mais freqüentemente isolados (Tab. 1) na OE foram: Bacillus sp. e $S$. intermedius; e para o ouvido médio prevaleceram: S. intermedius, $S$. aureus subsp. aureus e bacilos Gram-negativos não fermentadores. Não foram isoladas bactérias anaeróbias estritas nas amostras estudadas. 
Tabela 1. Espécies bacterianas isoladas em amostras de secreção auricular de ouvido externo e médio de cães otopatas

\begin{tabular}{|c|c|c|}
\hline & $\begin{array}{c}\text { Ouvido médio } \\
\mathrm{n}(\%)\end{array}$ & $\begin{array}{c}\text { Ouvido externo } \\
\mathrm{n}(\%)\end{array}$ \\
\hline \multicolumn{3}{|l|}{ Estafilococos/coagulase positiva } \\
\hline S. intermedius & $13(32,50)$ & $41(21,70)$ \\
\hline S. aureus subsp. aureus & $9(22,50)$ & $12(6,30)$ \\
\hline S. aureus subsp. anaerobius & $2(5,00)$ & $3(1,60)$ \\
\hline S. schleiferi subsp. coagulans & $1(2,50)$ & $3(1,60)$ \\
\hline S. hyicus & --- & $2(1,00)$ \\
\hline Staphylococcus sp. & --- & $1(0,50)$ \\
\hline Total & $25(62,50)$ & $62(32,80)$ \\
\hline \multicolumn{3}{|l|}{ Estafilococos coagulase negativa } \\
\hline S. xylosus & $2(5,00)$ & --- \\
\hline Staphylococcus sp. & --- & $1(0,50)$ \\
\hline Total & $2(5,00)$ & $1(0,50)$ \\
\hline \multicolumn{3}{|l|}{ Enterobactérias } \\
\hline K. pneumoniae & $1(2,50)$ & $3(1,60)$ \\
\hline E. coli & --- & $1(0,50)$ \\
\hline P. mirabilis & --- & $6(3,20)$ \\
\hline Enterobacter sp. & $1(2,50)$ & $5(2,60)$ \\
\hline C. freundii & --- & $1(0,50)$ \\
\hline Total & $2(5,00)$ & $16(8,50)$ \\
\hline \multicolumn{3}{|c|}{ Bacilos Gram-negativos não fermentadores } \\
\hline Não identificados & $4(10,00)$ & $1(0,50)$ \\
\hline P. aeruginosa & --- & $3(1,60)$ \\
\hline Total & $4(10,00)$ & $4(2,10)$ \\
\hline \multicolumn{3}{|l|}{ Outras } \\
\hline Bacillus sp. & $1(2,50)$ & $51(26,90)$ \\
\hline Micrococcus sp. & $1(2,50)$ & --- \\
\hline E. faecalis & $1(2,50)$ & --- \\
\hline Streptococcus sp. & $1(2,50)$ & $2(1,00)$ \\
\hline Total & $4(10,00)$ & $53(28,00)$ \\
\hline Total & $37(100)$ & $136(100)$ \\
\hline
\end{tabular}

Quanto ao isolamento fúngico, destacou-se a presença de $M$. pachydermatis no $\mathrm{OE}$, bem como a presença de outras espécies fúngicas leveduriformes $(C$. albicans, $C$. tropicalis, $C$. parapsilosis) e filamentosas (Trichophyton sp. e Aspergillus), associadas aos quadros de $\mathrm{OE}$ (Tab. 2).

Comparando-se os resultados positivos oriundos de amostras de OM $(\mathrm{n}=30)$ e OE $(\mathrm{n}=64)$, observou-se diferença qualitativa e quantitativa entre os perfis de isolamento em $96,7 \%$ dos casos.

A espécie bacteriana de importância clínica mais freqüentemente isolada foi o $S$. intermedius $(\mathrm{n}=54)$, portanto, os resultados do antibiograma são apresentados apenas para a referida espécie. Observou-se resistência a pelo menos um antimicrobiano em 55,6\% dos casos e multirresistência (dois ou mais antimicrobianos) em 35,2\% das cepas. Os antimicrobianos menos eficazes in vitro foram: eritromicina, penicilina $\mathrm{G}$, tetraciclina, clindamicina e ampicilina (Tab. 3).

\section{DISCUSSÃO}

O estudo mostrou diferenças no perfil de isolamento de microrganismos em $96,7 \%$ dos casos. Este resultado é muito importante para a terapêutica dessa doença e sugere que, nos casos de OE e OM caninas associadas, cada um desses sítios anatômicos deve ser avaliado individualmente no tocante aos procedimentos de cultura $\mathrm{e}$ antibiograma. Tal procedimento poderia auxiliar a resolução dos casos crônicos e refratários ao tratamento. 
Tabela 2. Espécies fúngicas isoladas em amostras de secreção auricular de ouvido externo e médio de cães otopatas

\begin{tabular}{lcc}
\hline & Ouvido médio & Ouvido externo \\
\hline Espécies leveduriformes & $\mathrm{n}(\%)$ & $\mathrm{n}(\%)$ \\
M. pachydermatis & $1(2,50)$ & $42(22,2)$ \\
C. albicans & $2(5,00)$ & $3(1,60)$ \\
C. tropicalis & -- & $3(1,60)$ \\
C. parapsilosis & --- & $1(0,50)$ \\
Total & $3(7,50)$ & $49(25,90)$ \\
Espécies filamentosas & & \\
Trichophyton sp. & --- & $1(0,50)$ \\
Aspergillus sp. & --- & $3(1,60)$ \\
Total & --- & $4(2,10)$ \\
\hline Total & $3(100)$ & $53(100)$ \\
\hline
\end{tabular}

O cálculo das porcentagens inclui as espécies bacterianas descritas na Tab. 1.

Tabela 3. Perfil de resistência (\%) a antimicrobianos de cepas de $S$. intermedius isoladas de secreção auricular de ouvido externo e médio de cães otopatas

\begin{tabular}{lc}
\hline Antimicrobiano & Resistência \\
\hline Aminoglicosídeos & 0,00 \\
Amicacina & 0,00 \\
Canamicina & 0,00 \\
Gentamicina & 0,00 \\
Neomicina & 0,00 \\
Tobramicina & \\
$\beta$-lactâmicos & 25,96 \\
Penicilina G & 16,67 \\
Ampicilina & 1,85 \\
Oxacilina & 0,00 \\
Imipeném & 0,00 \\
Cefalotina & 0,00 \\
Cefoxitina & 0,00 \\
Ticarcilina & \\
Quinolonas & 1,85 \\
Ciprofloxacina & 1,85 \\
Enrofloxacina & \\
Outros & 18,52 \\
Clindamicina & 27,78 \\
Eritromicina & 24,07 \\
Tetraciclina & 1,85 \\
Cloranfenicol & 11,11 \\
Sulfametoxazol- & \\
Trimetoprima & 0,00 \\
Polimixina B & 0,00 \\
Vancomicina &
\end{tabular}

A presença de sinais clínicos e a otoscopia são os principais procedimentos para o diagnóstico de otite externa canina (Harvey et al., 2004).
Bruyette e Lorenz (1993), ao abordarem o diagnóstico e os aspectos médicos relacionados à $\mathrm{OE}$ e OM caninas, mencionaram que o ato de balançar a cabeça e a visualização de traumatismos no pavilhão auricular são sinais comuns de otite externa, especialmente quando estão presentes corpos estranhos ou inflamação aguda. Nos animais avaliados neste estudo, a alteração clínica prevalente nos otopatas foi a presença de escoriações no pavilhão auricular $(72 \%)$.

Segundo Shell (1993), os sinais citados também podem ser indicativos de OM canina, acrescidos de outros, tais como: deficiência auditiva, otalgia e alteração no posicionamento da cabeça pelo excesso de dor. Esses resultados são confirmados neste estudo, no qual a segunda alteração clínica mais freqüente foi a presença de otalgia (12\%) e alteração do posicionamento do pavilhão auricular (12\%).

Harvey et al. (2004) afirmaram que, no exame otocópico, a presença de erosões e úlceras no conduto auditivo externo canino deve ser avaliada. Neste estudo, a ocorrência de pontos hemorrágicos $(87 \%)$ e de erosões $(80 \%)$ no conduto auditivo de otopatas foi a alteração mais freqüente. A presença de corpos estranhos foi a terceira alteração mais observada $(43 \%)$ e esteve em geral associada à infestação por carrapatos. August (1993) ressaltou que, apesar de as formas adultas do carrapato não parasitarem o conduto auditivo externo canino, suas larvas e ninfas podem induzir inflamações graves no local ao se 
alimentarem com sangue e linfa do epitélio do conduto auditivo.

A ruptura de MT foi observada em apenas 18\% dos animais otopatas, embora naqueles em que essa estrutura estava íntegra alguma alteração morfológica tenha sido sempre observada. Estes resultados assemelham-se aos descritos por Leite (1995) e Leite (2003), embora sejam inferiores aos de Cole et al. (1998), que observaram ruptura de MT em 28,9\% dos cães otopatas. Essa diferença pode ser atribuída ao fato de Cole et al. (1998) terem tido êxito na visualização da MT em todos os animais estudados, o que não ocorreu neste estudo. Little e Lane (1989) relataram que a dificuldade de visualização da MT em cães otopatas se deve à presença de estenose e ao acúmulo de cerúmen/exsudato no conduto auditivo.

A presença de eritrócitos na citologia implica contato íntimo com a vasculatura subjacente (Gotthelf, 2000) ou indica a presença de um componente hemorrágico como ulceração da epiderme (Chickering, 1993), o que condiz com a ocorrência de um quadro de OE. A presença de eritrócitos foi moderada nos cães otopatas (21\%) deste estudo, o que condiz com a presença de erosões e pontos hemorrágicos em cerca de $80 \%$ desses animais.

A observação de células inflamatórias (leucócitos e piócitos) na citologia auricular indica a ocorrência de um quadro ativo, surgindo inicialmente neutrófilos. De acordo com August (1993), a cronicidade da OE canina pode ser atestada em função da observação de macrófagos e fagossomas no esfregaço corado. Os resultados deste estudo confirmam os dados da literatura quanto à freqüência de células inflamatórias no exsudato de otopatas $(73 \%)$ e sua ausência no conduto auditivo de animais hígidos.

Nos casos de OE crônica, Harvey et al. (2004) afirmaram que o revestimento epitelial do conduto auditivo externo reage à inflamação e que a hiperplasia resulta em aumento no número de ceratinócitos e aparecimentos de epiteliócitos. Ginel et al. (2002) sugeriram que a alteração no processo de ceratinização é considerada um fator primário na gênese da $\mathrm{OE}$ canina. Os resultados deste estudo confirmaram a presença de um número maior que seis ceratinócitos/campo de imersão em $62 \%$ das amostras oriundas de ouvido externo de otopatas, enquanto nos animais hígidos esse percentual foi de $20 \%$.

O gênero Bacillus, de características reconhecidamente saprofíticas no ambiente auditivo canino, foi pouco citado em trabalhos de pesquisa. Entretanto, relatos de elevada taxa de isolamento desse microrganismo foram descritos por Leite (1995).

Vários estudos têm descrito a presença de microrganismos constituintes de uma microbiota normal no ouvido canino e têm demonstrado a associação entre $S$. intermedius e $M$. pachydermatis nos quadros de OE canina (Junco e Barrasa, 2002; Lilenbaum et al., 2000; Nobre et al., 2001). Embora alguns estudos considerem os estafilococos coagulase-negativos como o principal agente de OE canina (Lilenbaum et al., 2000), neste estudo o $S$. intermedius foi a bactéria mais freqüente. Este resultado assemelha-se aos relatados por Cole et al. (1998) e Hoekstra e Paulton (2002).

Cole et al. (1998), ao avaliarem as microbiotas presentes nos quadros de OM e OE canina associadas, observaram semelhança entre os isolamentos de $\mathrm{OM}$ e $\mathrm{OE}$ canina em apenas $10,5 \%$ das amostras. Diferenças no perfil de susceptibilidade a antimicrobianos entre amostras de $\mathrm{OM}$ e OE foram também observadas por esses autores, entre cepas de $S$. intermedius (26,3\%) e Pseudomonas sp. (23,7\%). A partir dessa observação, sugeriram que, nos quadros de OE crônica canina, em que se suspeita de OM associada, deve-se recorrer à coleta de material não apenas do ouvido externo, mas também do ouvido médio para realização de cultura e teste de susceptibilidade aos antimicrobianos a fim de escolher um tratamento direcionado e eficaz.

Tem-se observado um crescente interesse da área médica pelo $S$. intermedius. Estudos mostram a colonização de filhotes recém-nascidos pela referida espécie poucas horas após o nascimento (Saijonmaa-Koulumies e Lloyd, 2002). Além disso, tem sido demonstrado que as cepas virulentas de $S$. intermedius possuem considerável potencial enterotoxigênico (Becker et al., 2001) e produzem toxinas com propriedades de superantígenos (Hendricks et al., 2002). Esses achados tornam-se mais relevantes quando se considera evidente potencial zoonótico da espécie anteriormente 
descrito na literatura (Talan et al., 1989; Vandenesch et al., 1995; Terauchi et al., 2003).

M. pachydermatis é um microrganismo que compõe as microbiotas auricular e dérmica de carnívoros domésticos, embora possa apresentar patogenicidade em diversas situações (Mansfield et al., 1990; Leite et al., 2003). Para a OE, estes resultados assemelham-se aos relatados por Nobre et al., (2001) (76,5\%) e Crespo et al., 2000 $(68,4 \%)$. Quanto à $\mathrm{OM}$, os resultados confirmam os da literatura, demonstrando a pouca participação dos microrganismos fúngicos nesses quadros (Harvey et al., 2004).

Estudos têm abordado o efeito in vitro de antimicrobianos contra cepas de $S$. intermedius isoladas de cães. Tais trabalhos são de grande importância para a orientação do uso seletivo de quimioterápicos.

Macrolídeos são largamente utilizados na medicina veterinária, inclusive para o tratamento de infecções causadas por cepas de $S$. intermedius resistentes à penicilina e em pacientes alérgicos aos $\beta$-lactâmicos. Observouse resistência elevada à eritromicina e clindamicina, confirmando dados obtidos por outros autores (Kiss et al., 1997; Boerlin et al., 2001). Taxas de resistência mais elevadas foram obtidas por Magalhães et al. (1985). Essa divergência poderia ser justificada pelas diferenças regionais quanto ao uso de antimicrobianos.

Como esperado, a elevada resistência à penicilina $G$ e a moderada resistência à ampicilina poderiam ser explicadas pela produção de $\beta$-lactamases pelas cepas de $S$. intermedius, descritas por Shimizu et al. (2001) em $46,7 \%$ das cepas de $S$. intermedius de origem animal. Os resultados mostram percentuais de resistência inferiores aos descritos na literatura (Kiss et al., 1997; Cole et al., 1998).

As cepas de $S$. intermedius não mostraram resistência ao imipenem. O imipenem é um $\beta$ lactâmico pertencente ao grupo dos carbapenens e é resistente à hidrólise pela maioria das $\beta$ lactamases. Esse antimicrobiano não é utilizado, com freqüência, na medicina veterinária, o que poderia explicar a ocorrência de $100 \%$ de susceptibilidade observada neste estudo.
De forma semelhante, não foram isoladas cepas de $S$. intermedius resistentes à oxacilina. Este resultado assemelha-se ao descrito por Lilenbaum et al. (2000), os quais observaram $95,4 \%$ de susceptibilidade à oxacilina em cepas de Staphylococcus sp. isoladas de cães. Percentuais de resistência consideravelmente mais elevados têm sido relatados (Magalhães et al., 1985; Kiss et al., 1997). Essa diferença provavelmente se deve à metodologia empregada (não utilização do agar screen plate), à qualidade do disco de antibiótico usado e a nuances regionais relacionadas com a resistência local.

Considerando-se ainda o grupo dos $\beta$-lactâmicos, as cepas de $S$. intermedius não mostraram resistência à cefalotina e cefoxitina. Resultados semelhantes foram descritos por diversos autores, os quais relatam susceptibilidade às cefalosporinas em mais de $90 \%$ das cepas de $S$. intermedius isoladas de cães (Bornand, 1992; Cole et al., 1998). As variações descritas no perfil de resistência aos $\beta$-lactâmicos poderiam ser atribuídas às variações geográficas e aos hábitos de vida dos animais no tocante ao maior ou menor acesso às clínicas veterinárias e, conseqüentemente, ao arsenal de antimicrobianos.

O crescente aumento de resistência das cepas de Staphylococcus às tetraciclinas pode ser reflexo do uso excessivo desse antimicrobiano na medicina veterinária, especialmente para tratamento das afecções dermatológicas (Schwarz e Noble, 1999) . Cerca de $24 \%$ das cepas de $S$. intermedius mostraram resistência à tetraciclina, o que está de acordo com os relatos de Guedeja-Marron et al. (1998) e Shymizu et al. (2001). Percentuais mais elevados foram obtidos por outros autores (Boerlin et al., 2001; Hoekstra e Paulton, 2002). Para esse microrganismo, observou-se baixa resistência às quinolonas. Muitos trabalhos têm demonstrado a eficácia desses antimicrobianos contra cepas isoladas de amostras de origem canina (Junco e Barrasa, 2002; Hoekstra e Paulton, 2002). Entretanto, Junco e Barrasa (2002) alertaram para o uso indiscriminado de fluoroquinolonas, especialmente a enrofloxacina, que poderia resultar em aumento da taxa de resistência.

Neste estudo, não se observou resistência das cepas de $S$. intermedius aos aminoglicosídeos. Autores têm relatado a eficácia da tobramicina 
no tratamento tópico da OE canina, citando taxas de susceptibilidade que variam de $82 \%$ a $100 \%$ (Junco e Barrasa, 2002; Leite, 2003; Oliveira et al., 2005). O mesmo tem sido descrito para a gentamicina contra cepas de Staphylococcus sp. isoladas de OE canina, com taxas de susceptibilidade variando entre $90-100 \%$ na maioria dos estudos ao longo dos anos (Junco e Barrasa, 2002; Leite, 2003; Oliveira et al., 2005). No tocante a neomicina, os resultados diferem daqueles encontrados por outros autores, os quais relatam taxas de susceptibilidade inferiores a 80\% (Magalhães et al., 1985; Kiss et al., 1997; Junco e Barrasa, 2002).

O presente estudo enfatiza a necessidade de avaliação clínica individualizada nos quadros de otite externa e média canina associadas e reforça a importância da realização dos procedimentos de cultura e antibiograma para a escolha apropriada do antimicrobiano a ser adotado no tratamento dos referidos quadros.

\section{REFERÊNCIAS BIBLIOGRÁFICAS}

AUGUST J.R. Enfermedades del oído. Clin. Vet. North, Pract. Clin. Peq. Anim., v.18, p.1-274, 1993.

BECKER, K.; KELLER, B.; EIFF, C. et al. Enterotoxigenic potential of Staphylococcus intermedius. Appl. Env. Mic., v.67, p.5551-5557, 2001.

BOERLIN, P.; BURNENS, A. P.; FREY, J. et al. Molecular epidemiology and genetic linkage of macrolide and aminoglycoside resistance in Staphyloccus intermedius of canine origin. Vet. Microbiol., v.79, p.155-169, 2001.

BONATES, A. Otite: conhecimento detalhado permite diagnósticos precisos e sucesso no tratamento. Vet. News, v.62, p.6-8, 2003.

BORNAND, V. Bacteriology and mycology of otitis externa in dogs. Schweiz Arch Tierheilkd., v.134, p.341-348, 1992.

BRUYETTE, D.S.; LORENZ, M.D. Otitis externa and media: diagnostic and medical aspects. Sem. Vet. Med. Surg. Small Anim., v.8, p.3-9, 1993.

CHICKERING, W.R. Evaluación citológica de los exudatos en las otitis. Clin. Vet. North, Pract. Clin. Peq. Anim., v.18, p.51-62, 1993.
COLE, L.K.; KWOCHKA, K.W.; KAWALKI, J.J. et al. Microbial flora and antimicrobial susceptibility patterns of isolated pathogens from the horizontal ear and middle ear dogs with otitis media. J. Am. Vet. Med. Assoc., v.212, p.534538, 1998 .

CRESPO, M.J.; ABARCA, M.L.; CABANES, M.L. Atypical lipid-dependent Malassezia species isolated from dogs with otitis externa. $J$. Clin. Microbiol., v.38, p.2383-2385, 2000.

GOTTHELF, L.N. Small animal ear disease. Philadelphia: W.B. Saunders, 2000. 270p.

GREENE, C.E. Enfermidades infecciosas: perros y gatos. Editora Interamericana, 1993.

GUADEJA-MARROM, S.S.; BLANCO, J.L.; RUPEREZ, G.; GARCIA, M.E. Susceptibility of bacterial isolates from chronic canine otitis externa to twenty antibiotics. Vet. Med. B, v.48, p.507-512, 1998.

HARVEY, R.G.; HARARI, J.; DELAUCHE, A.J. Doenças do ouvido de cães e gatos. Rio de Janeiro: Editora Revinter, 2004. 272p.

HENDRICKS, A.; SCHUBERTH, H.; SCHUELER, K. et al. Frequency of superantigen-producing Staphylococcus intermedius isolates from canine pyoderma and proliferation-inducing potential of superantigens in dogs. Res. Vet. Sci., v.73, p.273-277, 2002.

HOEKSTRA, K. A.; PAULTON, R. J. L. Clinical prevalence and antimicrobial susceptibility of Staphylococcus aureus and Staphylococcus intermedius in dogs. J. Appl., v.93, p.406-413, 2002.

JUNCO, M.T.T.; BARRASA, J.T.M. Identification and antimicrobial susceptibility of coagulase positive Staphylococci isolated from healthy and dogs suffering from otitis externa. $J$. Vet. Med. B, v.49, p.419-423, 2002.

KISS, G.; RADVAYI, S.Z.; SZIGETI, G. New combination for the therapy of canine otitis externa. I - Microbiology of otitis externa. J. Small Anim. Pract., v.38, p.51-56, 1997.

LEITE, C.A.L. Caracterização clínica e laboratorial de caninos hígidos e otopatas, com ênfase na microbiota aeróbica e anaeróbica dos condutos auditivos. 2003. 237f. Tese (Doutorado) - Faculdade de Medicina Veterinária e Zootecnia, Universidade Estadual Paulista, Botucatú, SP. 
LEITE, C.A.L. Isolamento, identificação e sensibilidade de agentes microbianos causadores de otite em cães (Canis familiaris). 1995. 60f. Dissertação (Mestrado), Escola de Veterinária, Universidade Federal de Minas Gerais, Belo Horizonte.

LEITE, C.A.L.; ABREU, V.L.V.; COSTA, G.M. Freqüência de Malassezia pachydermatis em otite externa de cães. Arq. Bras. Med. Vet. Zootec., v.55, p.102-104, 2003.

LILENBAUM, W.; VERAS, M.; BLUM, E. et al. Antimicrobial susceptibility of Staphylococci isolated from otitis externa in dogs. Lett. Appl. Microbiol., v.31, p.42-45, 2000.

LITTLE, C.J.L.; LANE, J.G. An evaluation of tympanometry, otoscopy, and palpation for assessment of the canine tympanic membrane. Vet. Rec., v.124, p.5-8, 1989.

MAGALHÃES, M.J.; SILVA, N.; MARQUES Jr., A.P. Otite externa em cães atendidos no Hospital Veterinário da UFMG: etiologia, freqüência e sensibilidade antibiótica. Arq. Bras. Med. Vet. Zootec., v.37, p.333-341, 1985.

MANSFIELD, P.D.; BOOSINGER, T.R.; ATTLEBERGER, M.H. Infectivity of Malassezia pachydermatis in the external ear canal of dogs. J. Am. Anim. Health Assoc., v.26, p.97-100, 1990.

MATSUDA, H.; TOJO, M.; FUKUI, K. et al. The aerobic bacterial flora of the middle and external ears in normal dogs. J. Small Anim. Pract., v.25, p.269-274, 1984.

MURRAY, P.R.; ROSENTHAL, K.S.; KOBAYASHI, G.S. et al. Medical microbiology. 4.ed. Mosby, 2002. p.4-687.

NOBRE, M.O.; CASTRO, A.P.; NASCENTE, P.S. et al. Occurrency of Malassezia pachydermatis and other infectious agents as cause of external otitis in dogs from Rio Grande do Sul State, Brazil (1996,1997). Braz. J. Microbiol.,v.32, p.243-247, 2001.

OLIVEIRA, L.C.; MEDEIROS, C.M.O.; SILVA, I.N.G. et al. Susceptibilidade a antimicrobianos de bactérias isoladas de otite externa em cães. Arq. Bras. Med. Vet. Zootec., v.57, p.405-408, 2005.

PERFORMANCE Standards for Antimicrobial Disk and Dilution Susceptibility Tests for Bacteria Isolated from Animals; Tentative Standard NCCLS Document M31-T (ISBNI56238-330-2), 940 West Valley Road, Suite 1400, Wayne Pennsylvania 19887, USA, 1997

SAIJONMAA-KOULUMIES; LLOYD, D.H. Colonization of neonatal puppies by $S$. intermedius. Vet. Dermatol., v.13, p.123-130, 2002.

SCHWARZ, S.; NOBLE, W.C. Aspects of bacterial resistance to antimicrobials used in veterinary dermatology practice. Vet. Dermatol., v.10, p.163-176, 1999.

SHIMIZU, A.; WAKITA, Y.; NAGASE, S. et al. Antimicrobial susceptibility of Staphylococcus intermedius isolated from healthy and diseased dogs. J. Vet. Med. Sci., v.63, p.357-360, 2001.

SIDRIM, J.J.C.; MOREIRA, J.L.B. Fundamentos clínicos e laboratoriais $d a$ micologia médica. Rio de Janeiro: Guanabara Koogan, 1999. 287p.

SMITH, M.M.; WALDRON, D.R. Atlas of approaches for general surgery of the dog and cat. Philadelphia: W.B.Saunders, 1993. 398p.

TALAN, D. A.; STAATZ, D.; STAATZ, A. et al. Staphylococcus intermedius in canine gingival and canine-inflicted human wound infections: laboratory characterization of a newly recognized zoonotic pathogen. J. Clin. Microbiol., v.27, p.78-81, 1989.

TERAUCHI, R.; SATO, H.; HASEGAWA, T. et al. Isolation of exfoliative toxin from Staphylococcus intermedius and its local toxicity in dogs. Vet. Microbiol., v.94, p.19-29, 2003.

VANDENESCH, F.; CELARD, M.; ARPIN, D. et al. Catheter-related bacteremia associated with coagulase-positive Staphylococcus intermedius. J. Clin. Microbiol., v.33, p.2508-2510, 1995. 